\title{
Article \\ Computational Approach for the Fluid-Structure Interaction Design of Insect-Inspired Micro Flapping Wings
}

\author{
Daisuke Ishihara (D)
}

check for updates

Citation: Ishihara, D. Computational Approach for the Fluid-Structure Interaction Design of Insect-Inspired Micro Flapping Wings. Fluids 2022, 7, 26. https://doi.org/10.3390/ fluids7010026

Academic Editors: Rajat Mittal, Hao Liu and Kourosh Shoele

Received: 30 November 2021

Accepted: 4 January 2022

Published: 6 January 2022

Publisher's Note: MDPI stays neutral with regard to jurisdictional claims in published maps and institutional affiliations.

Copyright: (C) 2022 by the author. Licensee MDPI, Basel, Switzerland. This article is an open access article distributed under the terms and conditions of the Creative Commons Attribution (CC BY) license (https:// creativecommons.org/licenses/by/ $4.0 /)$
Department of Intelligent and Control Systems, Kyushu Institute of Technology, Fukuoka 8208502, Japan; ishihara.daisuke399@mail.kyutech.jp

\begin{abstract}
A flight device for insect-inspired flapping wing nano air vehicles (FWNAVs), which consists of the micro wings, the actuator, and the transmission, can use the fluid-structure interaction (FSI) to create the characteristic motions of the flapping wings. This design will be essential for further miniaturization of FWNAVs, since it will reduce the mechanical and electrical complexities of the flight device. Computational approaches will be necessary for this biomimetic concept because of the complexity of the FSI. Hence, in this study, a computational approach for the FSI design of insect-inspired micro flapping wings is proposed. This approach consists of a direct numerical modeling of the strongly coupled FSI, the dynamic similarity framework, and the design window (DW) search. The present numerical examples demonstrated that the dynamic similarity framework works well to make different two FSI systems with the strong coupling dynamically similar to each other, and this framework works as the guideline for the systematic investigation of the effect of characteristic parameters on the FSI system. Finally, an insect-inspired micro flapping wing with the 2.5-dimensional structure was designed using the proposed approach such that it can create the lift sufficient to support the weight of small insects. The existing area of satisfactory design solutions or the DW increases the fabricability of this wing using micromachining techniques based on the photolithography in the micro-electro-mechanical systems (MEMS) technology. Hence, the proposed approach will contribute to the further miniaturization of FWNAVs.
\end{abstract}

Keywords: insect flapping flight; fluid-structure interaction design; flapping wing nano air vehicle (FWNAV); computational biomimetics; finite element method

\section{Introduction}

The advantages of flight over other forms of locomotion have resulted in the dispersal of insects on Earth [1]. They can perform extreme aerial maneuvers with robustness using flapping wings [2]. Their flight abilities have become increasingly refined through a long period of natural selection [3]. Hence, emulating nature's time-tested forms, functions, and strategies in flying insects with understanding their underlying mechanisms leads to finding sustainable solutions [4,5], which are engineering alternatives to nature's solutions. This biomimetic concept is multidisciplinary. Hence, computational approaches for this biomimetic concept will be essential because of their interdisciplinary feature, leading to the computational biomimetics.

This study focuses on insect-inspired flapping wing nano air vehicles (FWNAVs) whose sizes range from approximately 1 to $10 \mathrm{~cm}$ [6], on which various research groups are working as one of most popular topics in the biomimetic research area. One engineering concern in the development of FWNAVs is the reduction of their size [7,8], potentially down to the size scale of very small insects, of which wingspan length is less than $1 \mathrm{~mm}$ as the result of the evolution [9].

Similar to the structural design of micro-electro-mechanical systems [10], the conceptual, basic, and detailed design processes of FWNAVs will be indistinguishable from each other, because of the novelty of the biomimetic concept, and the formulation as a single 
design problem is difficult in each design process. Furthermore, the feasibility of the design solution is strongly constrained by the manufacturability, which is hardly formulated as the design problem.

The flight ability of the insects seems to be determined by the characteristic motions of their flapping wings such as the pitching, the cambering, and the wing's tip path [11]. In particular, the pitching motion will be the kinematical basis of the aerodynamics of the insect flapping flight [12]. The insect wings and their base are flexible [13-19]. Hence, their flapping motion with the large stroke angle [20] causes their deformation due to the aerodynamic force from the surrounding air, and their deformation causes the change of the surrounding air flow, which results in the change of the aerodynamic force. Recent advances on this topic are given mainly by the computational approaches using the computational fluid dynamics [21-25] and the numerical fluid-structure interaction (FSI) analysis [26-33]. Some studies used the experimental approaches $[22,29,34]$. Some of them have shown that the wing's characteristic motions can be caused by the strong coupling between the wing and the surrounding air [26,28-30,32,34].

In the FSI design [35], a flight device for FWNAVs, which consists of the micro wings, the actuator, and the transmission [6], actively uses the FSI to create the characteristic wing's motions. It can reduce the mechanical and electrical complexities of this device [36]. Hence, it is essential for further miniaturization of FWNAVs. Computational approaches are necessary for this biomimetic concept because of the complexity of the FSI. However, there are few studies focusing on this topic.

Hence, in this study, a computational approach for the FSI design of insect-inspired micro flapping wings is proposed. This approach consists of a direct numerical modeling of the strongly coupled FSI, the dynamic similarity framework, and the design window (DW) search. Here, the term "direct" means that, prior to the finite element discretization, the governing equations are not transformed into a different form [37].

The key of the FSI design is the accurate prediction for three-dimensional (3-D) strong coupling of a thin flexible flapping wing and the surrounding air flow. Here, a projection method using the algebraic splitting $[38,39]$ is used to solve this problem directly.

The dynamic similarity law for the FSI $[26,29,30,32,34]$ is used as the framework for the systematic treatment of FSI complexities. The validity of this framework is demonstrated in the first numerical example. As shown in the second numerical example, the simulation based on the direct numerical modeling for the strong coupling of the lumped flexibility model [26,32] and the surrounding fluid is guided by this framework, and the underlying mechanism is effectively investigated, which is the basis of the FSI design.

DWs are the existing areas of satisfactory solutions in a design parameter space. They can adapt to changes in the design problem. Hence, the DW search is effective for the above-mentioned issues in the design of FWNAVs.

Finally, in the last numerical example, an insect-inspired micro flapping wing with the 2.5-dimensional (2.5-D) structure is designed using the proposed approach. The 2.5-D structure is multi-layered, and each layer is given by laminating the membrane or the thin plate on the flat layer already developed and etching it to form the in-plane shape. This structure can be fabricated using the micromachining based on the photolithography in the micro-electro-mechanical systems (MEMS) technology. However, there exists the strong restriction on the shape in the out-of-plane direction. The DW is determined such that each solution in the DW can create the lift sufficient to support the weight of small insects. This wing can be fabricated using the micromachining based on the photolithography $[7,8,40,41]$. Hence, the proposed approach will contribute to the further miniaturization of FWNAVs.

\section{Fluid-Structure Interaction Design Approach}

2.1. Model Wing for the Fluid-Structure Interaction Design

In the FSI design [35], a flight device for FWNAVs consisting of the micro flapping wings, the actuator, and the transmission [6] actively uses the FSI to create the characteristic 
motions of the wings. This concept will reduce the mechanical and electrical complexities of this device [36], which leads to further miniaturization of FWNAVs.

The wings of actual insects consist of multiple and multilayered structures spanning a wide range of length scale $[13,42-45]$. The wing's veins and membranes keep enough strength against loads during the flight [13], while these structures allow their characteristic deformations such as the twisting and the cambering [11,46], which improve the aerodynamic performance [22-25,27,31]. Recent advances on this topic such as References [18,19] will improve the understanding for the material mechanics of the insects' wings.

The wing base consists of steering muscles and tendons with both flexible and rigid parts that work together as a transmission to redirect power from the main flight muscles to the wing's flapping while to allow the fine-tuned wing's control [47-50].

It seems that there exist two approaches for modeling these structures [51]. One is the reduced-order modeling [26,27,29,32,52-54], and the other is the realistic modeling [55-57]. In References [26,29,32], the lumped flexibility model is used, where the spring encapsulates the detailed structures as the macroscopic constitutive relationship that describes their elastic mechanism. In Reference [29], the continuous constitutive relationship like anisotropic materials is used. In References [52-54], the structural elements such as beam, membrane, and shell are used. The reduced-order modeling can be incorporated in the computational FSI analysis using the current computer resources [26,27,29,32]. Hence, in this study, the lumped flexibility model is used.

The basic model wing for the FSI design is shown in Figure 1, where the spring for the torsion corresponds to the torsional flexibility that generates the wing's pitching motion $[26,29]$, the spring for the elevation corresponds to the elevation flexibility that generates the wing's tip path [32], and the spring for the flapping corresponds to the transmission for the wing's flapping. Furthermore, the veins are represented by three beams according to their functions to form the camber [52-54]. This model wing emulates the characteristic wing's motions with their elastic mechanisms and leads to the engineering alternatives to the nature's solution.

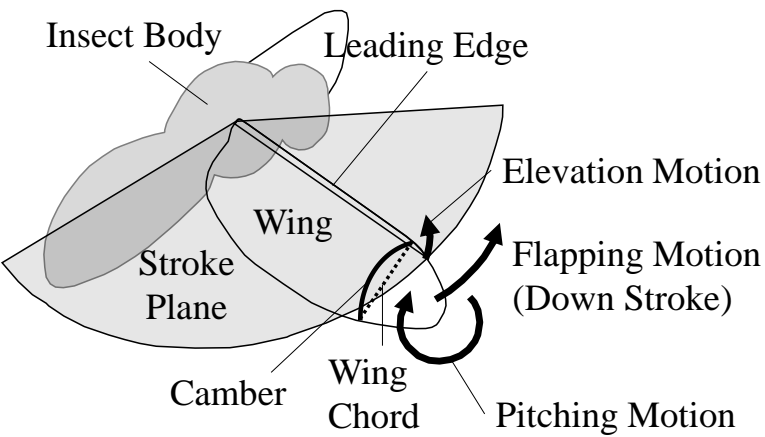

(a)

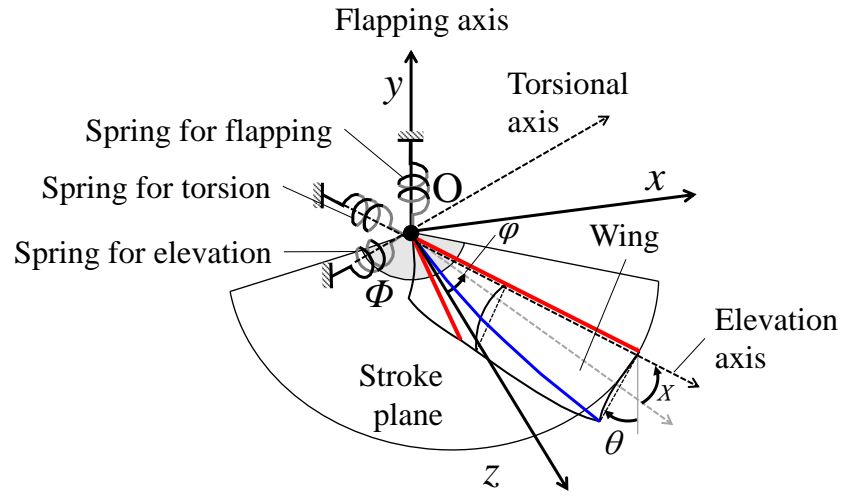

(b)

Figure 1. Modeling of the insect flapping wing: (a) Schematic view of the insect flapping wing; (b) The basic model wing for the FSI design with the springs of flapping, torsion, and elevation, which correspond to the axes of flapping, torsion, and elevation, respectively. $\Phi$ is the stroke angle, $\varphi$ is the stroke angular displacement, $\theta$ is the pitching angular displacement, and $\chi$ is the elevation angular displacement.

\subsection{Fluid-Structure Interaction Analysis}

The key of the FSI design is the accurate prediction for the 3-D strong coupling of the thin flexible flapping wing and the surrounding air flow. Here, a projection method using the algebraic splitting $[38,39]$ solves this problem directly. This method was validated using the benchmarks in References [38,39]. The computer program used in this study was also 
validated in Reference [29] using the actual experiment of the dynamically scaled model, which is similar to the FSI problem in this study.

\subsubsection{Governing Equations for the FSI}

The equilibrium equation for the elastic wing can be expressed as

$$
\rho^{\mathrm{s}} \frac{\mathrm{d} v^{\mathrm{s}}{ }_{i}}{\mathrm{~d} t}=\frac{\partial \sigma^{\mathrm{s}}{ }_{i j}}{\partial x_{j}}
$$

where $\mathrm{d} / \mathrm{d} t$ in the left-hand side is the Lagrangian time derivative, the superscript $\mathrm{s}$ indicates a quantity corresponding to the structure, $\rho^{\mathrm{s}}$ is the mass density of the structure, $v^{\mathrm{s}}{ }_{i}$ is the $i$-th component of the structural velocity vector, and $\sigma^{\mathrm{s}}{ }_{i j}$ is the $i j$-th component of the Cauchy stress tensor of the structure. Note that $i$ equals 1,2 , or 3 , and corresponds to the $x, y$, or $z$ direction, respectively, in the Cartesian coordinate system.

The incompressible Navier-Stokes (NS) equations for the fluid can be expressed as

$$
\begin{gathered}
\rho^{\mathrm{f}} \frac{\partial v^{\mathrm{f}} i}{\partial t}+\rho^{\mathrm{f}}\left(v^{\mathrm{f}}{ }_{j}-v^{\mathrm{m}}{ }_{j}\right) \frac{\partial v^{\mathrm{f}}}{\partial x_{j}}=\frac{\partial \sigma^{\mathrm{f}}{ }_{i j}}{\partial x_{j}} \\
\frac{\partial v^{\mathrm{f}}}{\partial x_{i}}=0
\end{gathered}
$$

where the arbitrary Lagrangian-Eulerian (ALE) method is used, $\partial / \partial t$ in the left-hand side is the ALE time derivative, the superscript $\mathrm{f}$ indicates a quantity corresponding to the fluid, $\rho^{\mathrm{f}}$ is the mass density of the fluid, $v^{\mathrm{f}}{ }_{i}$ is the $i$-th component of the fluid velocity vector, $v^{\mathrm{m}}{ }_{i}$ is the $i$-th component of the velocity vector of the ALE coordinate, and $\sigma^{\mathrm{f}}{ }_{i j}$ is the $i j$-th component of the Cauchy stress tensor of the fluid.

The interface conditions describing the interaction between the wing and the surrounding fluid can be expressed as

$$
\begin{gathered}
\sigma^{\mathrm{f}}{ }_{i j} n_{j}^{\mathrm{f}}+\sigma^{\mathrm{s}}{ }_{i j} n_{j}^{\mathrm{s}}=0 \\
v^{\mathrm{f}}{ }_{i}=v^{\mathrm{s}}{ }_{i}
\end{gathered}
$$

where $n^{\mathrm{f}}{ }_{i}$ and $n^{\mathrm{s}}{ }_{i}$ are the $i$-th components of the outward unit normal vectors on the fluid-structure interface corresponding to the fluid and the structure, respectively.

\subsubsection{Monolithic Equation System for the FSI}

Applying finite element discretization to the total Lagrangian formulation of Equation (1), the nonlinear equilibrium equation system is obtained in matrix form. Similarly, applying finite element discretization to Equations (2) and (3), the nonlinear equation system is obtained in matrix form. Applying the fluid-structure interface conditions (4) and (5) to the spatially discretized governing equations, the monolithic equilibrium equations and the incompressibility constraint for the fluid can be obtained as follows:

$$
\begin{gathered}
{ }_{\mathrm{L}} \mathbf{M a}+\mathbf{C} \mathbf{v}+\mathbf{N}+\mathbf{q}(\mathbf{u})-\mathbf{G} \mathbf{p}=\mathbf{g} \\
{ }_{\tau} \mathbf{G} \mathbf{v}=0
\end{gathered}
$$

where $\mathbf{M}$ is the mass matrix, $\mathbf{C}$ is the diffusive matrix, $\mathbf{G}$ is the divergence operator matrix, $\mathbf{N}$ is the convective term vector, $\mathbf{q}$ is the elastic internal force vector, $\mathbf{g}$ is the external force vector, $\mathbf{a}$ is the acceleration vector, $\mathbf{v}$ is the velocity vector, $\mathbf{u}$ is the displacement vector, $\mathbf{p}$ is the pressure vector, the subscript $L$ indicates the lumping of the matrix, and the subscript $\tau$ indicates the transpose of the matrix.

The monolithic Equations (6) and (7) are linearized using the increments of the state variables as follows:

$$
\mathbf{M}^{*} \Delta \mathbf{a}-\mathbf{G} \Delta \mathbf{p}=\Delta \mathbf{g}
$$




$$
\gamma \Delta t_{\tau} \mathbf{G} \Delta \mathbf{a}+\mathbf{G}_{\varepsilon} \Delta \mathbf{p}=\Delta \mathbf{h}
$$

where the pressure term and the elastic interior force term are evaluated implicitly, $\mathbf{M}^{*}$ is the generalized mass matrix, $\Delta t$ denotes the time increment, $\Delta \mathbf{g}$ and $\Delta \mathbf{h}$ are the residual vectors of the equilibrium Equation (6) and the incompressibility constraint (7), respectively, $\mathbf{G}_{\varepsilon}$ comes from the pressure stabilization term of the PSPG method. The relations between the increments of the state variables are given as $\Delta \mathbf{u}=\beta \Delta t^{2} \Delta \mathbf{a}$ and $\Delta \mathbf{v}=\gamma \Delta t \Delta \mathbf{a}$ using the Newmark's $\beta$ method.

The fluid convection and diffusion terms are evaluated explicitly to reduce the computational cost. Therefore, $\mathbf{M}^{*}$ is given as ${ }_{\mathrm{L}} \mathbf{M}+\beta \Delta t^{2} \mathbf{K}$, while the Courant's and diffusion number conditions are imposed on the time increment $\Delta t$ for the stability of the time integration. The predictor-multicorrector algorithm (PMA) is used for the time integration.

\subsubsection{Projection Method Using the Algebraic Splitting}

The monolithic method solves the linearized monolithic Equations (8) and (9) simultaneously. Hence, this method can satisfy the interface conditions (4) and (5) to avoid spurious numerical power on the fluid-structure interface, which yields numerical instability. However, the formulation might lead to ill-conditioned coefficient matrices. In this study, the projection method using the algebraic splitting $[38,39]$ is used to avoid this difficulty. This method is briefly described as follows:

The state variables are predicted as the intermediate state variables from the equilibrium Equation (6) for the known pressure, which can be linearized as

$$
\mathbf{M}^{*} \Delta \mathbf{a}^{*}=\Delta \mathbf{g}
$$

where $\mathbf{a}^{*}$ is the intermediate acceleration or the acceleration predictor, and $\Delta$ is the increment from the known variable. Subtracting both sides of Equation (10) from those of Equation (8) gives, after suitable rearrangement,

$$
\gamma \Delta t \mathbf{G} \Delta \mathbf{p}=\mathbf{M}^{*}\left(\mathbf{v}-\mathbf{v}^{*}\right)
$$

where $\mathbf{v}^{*}$ is the intermediate velocity or the velocity predictor. The relations between the increments of the intermediate state variables are given as $\Delta \mathbf{u}^{*}=\beta \Delta t^{2} \Delta \mathbf{a}^{*}$ and $\Delta \mathbf{v}^{*}=\gamma \Delta t \Delta \mathbf{a}^{*}$ using the Newmark's $\beta$ method.

Left multiplying both sides of Equation (11) by ${ }_{\tau} \mathbf{G}_{\mathrm{L}} \mathbf{M}^{-1}$, the following equation is obtained:

$$
\gamma \Delta t_{\tau} \mathbf{G}_{\mathrm{L}} \mathbf{M}^{-1} \mathbf{G} \Delta \mathbf{p}={ }_{\tau} \mathbf{G} \mathbf{v}-{ }_{\tau} \mathbf{G} \mathbf{v}^{*}+{ }_{\tau} \mathbf{G}_{\mathrm{L}} \mathbf{M}^{-1} \stackrel{-*}{\mathbf{M}}\left(\mathbf{v}-\mathbf{v}^{*}\right)
$$

where $\mathbf{M}$ is defined as $\mathbf{M}^{*}-{ }_{\mathrm{L}} \mathbf{M}$. If the following pressure Poisson equation (PPE)

$$
\gamma \Delta t_{\tau} \mathbf{G}_{\mathrm{L}} \mathbf{M}^{-1} \mathbf{G} \Delta \mathbf{p}=-{ }_{\tau} \mathbf{G v}^{*}
$$

is solved, then Equation (12) is reduced as

$$
{ }_{\tau} \mathbf{G v}+{ }_{\tau} \mathbf{G}_{\mathrm{L}} \mathbf{M}^{-1} \stackrel{-*}{\mathbf{M}}\left(\mathbf{v}-\mathbf{v}^{*}\right)=0
$$

If the linear convergence of the state variables is assumed, $\mathbf{v}^{*}$ agrees with $\mathbf{v}$ asymptotically in the nonlinear iterations. Therefore, the second term of Equation (14) will vanish asymptotically, and the incompressibility constraint for the unknown fluid velocity will be satisfied.

It follows from the above formulation that the monolithic equation system is split into the two equilibrium Equations (8) and (10), and the PPE (13). In the nonlinear iterations, the linearized equilibrium equation for the previous pressure (10) is solved to derive the intermediate velocity, the PPE (13) is solved to determine the current pressure such that 
the current velocity field satisfies the incompressibility constraint (7), and the linearized equilibrium equation for the current pressure (8) is solved to derive the current velocity.

\subsubsection{Parallel Computation}

The following matrix-vector product is considered, since it is most expensive computation in the iterative solvers for Equations (8), (10) and (13):

$$
{ }_{\tau} \mathbf{G}_{\mathrm{L}} \mathbf{M}^{-1} \mathbf{G} \Delta \mathbf{p}
$$

Assuming that the number of degrees of freedoms (DOFs) of the shell structure is far smaller than that of the fluid, the following parallel solution procedure is used based on the mesh decomposition. The mesh is decomposed as shown in Figure 2. The symbols $\Omega_{\mathrm{S}}$ and $\Omega_{\mathrm{F}}$ denote the structural and fluid meshes, respectively, and $\Omega_{\mathrm{F} i}\left(i=1,2, \ldots, N_{\mathrm{d}}\right)$ denotes $i$-th submesh of $\Omega_{\mathrm{F}}$. Note that $\Omega_{\mathrm{S}}$ is set inside $\Omega_{\mathrm{F} 1}$ as shown in Figure 2 under the above-mentioned assumption. In this case, the matrix-vector product concerning the fluid-structure interface can be computed at one computational node, and the complexity of the computer implementation is reduced. The computation concerning $\Omega_{\mathrm{F} i}$ is executed at the computational node $\mathrm{P}_{i}\left(i=1,2, \ldots, N_{\mathrm{d}}\right)$, while the computation concerning $\Omega_{\mathrm{S}}$ is executed at $P_{1}$. Using the above setup, the matrix-vector product (15) is computed as follows:

- $\quad$ Step 1. The matrix-vector product (15) is independently computed at $P_{i}(i=1,2, \ldots$, $N_{\mathrm{d}}$ ) using the element-by-element method as

$$
\mathbf{A} \mathbf{p}=\sum_{e} \mathbf{A}^{(e)} \mathbf{p}^{(e)}=\sum_{e} \mathbf{q}^{(e)}=\mathbf{q}
$$

where A denotes the global matrix, $\mathbf{p}$ denotes the global vector, $\mathbf{q}$ denotes their matrixvector product, $\mathbf{A}^{(e)}$ and $\mathbf{p}^{(e)}$ are their elemental counterparts, respectively, and $e$ denotes the element number.

- $\quad$ Step 2. The nodal data of the matrix-vector product (16) on the interface between $\Omega_{\mathrm{F} i}$ and $\Omega_{\mathrm{Fj}}(j \neq i)$ computed at $\mathrm{P}_{j}$ is transferred to $\mathrm{P}_{i}$ and added to complete the corresponding nodal data computed in Step 1 .

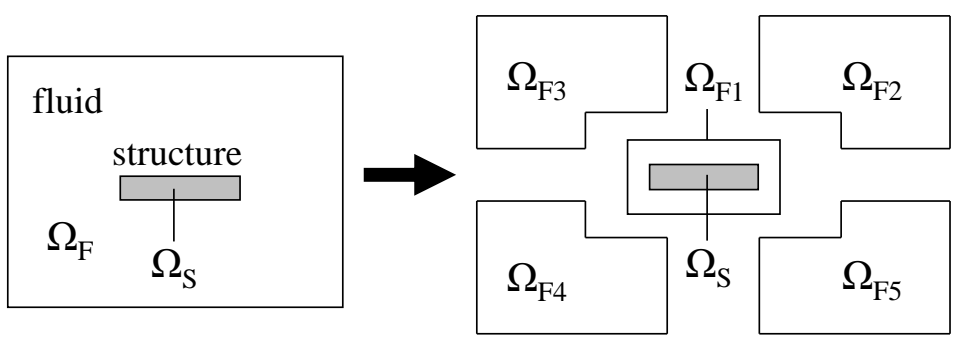

Figure 2. Mesh decomposition.

\subsubsection{Shell Modeling of the Thin Elastic Wing}

In this study, mixed interpolation of tensorial components (MITC) shell elements [58,59] are used for a thin elastic wing, while linear equal-order-interpolation velocity-pressure elements [60] are used for the fluid. The same arrangements of the fluid and shell nodes on the fluid-structure interface [61] are used. Hence, a pair of two overlapping fluid nodes per one shell node on the fluid-structure interface is necessary to describe the pressure discontinuity between the obverse and reverse of the shell structure. The interface conditions (4) and (5) are rewritten in matrix form as

$$
\begin{gathered}
\mathbf{v}_{\mathrm{c}}^{\mathrm{f}}={ }_{\tau} \mathbf{T}_{\mathbf{v}_{\mathrm{c}}} \\
\mathbf{T} \mathbf{Q}_{\mathrm{c}}^{\mathrm{f}}+\mathbf{Q}^{\mathrm{s}}{ }_{\mathrm{c}}=\mathbf{g}^{\mathrm{fs}}{ }_{\mathrm{c}}
\end{gathered}
$$


where $\mathbf{Q}$ is the internal force vector including all effects of the fluid or the structure, $\mathbf{T}$ is the interpolation matrix, and the subscript $c$ indicates the coupled DOFs. The nodal expressions of these equations are

$$
\begin{gathered}
\left\{\begin{array}{l}
{ }_{{ }^{o}} v^{\mathrm{f}}{ }^{\mathrm{c}} \\
{ }_{\mathrm{r}} v^{\mathrm{f}}{ }_{\mathrm{c}}
\end{array}\right\}=\left[\begin{array}{l}
1 \\
1
\end{array}\right] v^{\mathrm{s}}{ }_{\mathrm{c}} \\
{\left[\begin{array}{ll}
1 & 1
\end{array}\right]\left\{\begin{array}{l}
{ }_{\mathrm{o}} Q^{\mathrm{f}}{ }_{\mathrm{c}}^{\mathrm{c}} \\
{ }_{\mathrm{r}} Q^{\mathrm{f}}{ }_{\mathrm{c}}
\end{array}\right\}+Q^{\mathrm{s}}{ }_{\mathrm{c}}=g^{\mathrm{fs}}{ }_{\mathrm{c}}}
\end{gathered}
$$

where $v, Q$, and $g$ are the nodal components of the velocity, and the internal and external force vectors, respectively, and the subscripts o and $r$ indicate the obverse and reverse sides of the shell structure, respectively.

\subsection{Dynamic Similarity Framework for the FSI}

The dynamic similarity law can be used to correctly incorporate morphological and kinematical data from actual insects into model wings. Initially, the dynamic similarity law for the fluid dynamics was used for the experimental model [12,62]. The dynamic similarity law for the FSI was first introduced in the numerical model [26], and then it was used for the experimental model [34]. In this study, it is used as the framework for the systematic treatment for the complexities of the FSI.

The nondimensional parameter $\alpha$, the Reynolds number $\mathrm{Re}$, the Cauchy number $\mathrm{Ca}$, which represents the ratio of the fluid dynamic pressure to the structural elastic force, and the mass ratio $M_{R}$ are obtained from the dimensional analysis for the governing Equations (1)-(4) with respect to the characteristic length $L$, the characteristic velocity $V$, and the characteristic time $T$ as follows:

$$
\begin{gathered}
\alpha=L /(T V) \\
\operatorname{Re}=\rho^{\mathrm{f}} L V / \mu^{\mathrm{f}} \\
\mathrm{Ca}=\rho^{\mathrm{f}} V^{2} L^{3} C \\
M_{\mathrm{R}}=m_{\mathrm{w}} /\left(\rho^{\mathrm{f}} L^{3}\right)
\end{gathered}
$$

where $\mu^{\mathrm{f}}$ is the fluid viscosity, $C$ is the wing's compliance, and $m_{\mathrm{w}}$ is the wing's mass. The parameter (21) is the ratio of the inertial force due to the local acceleration to that due to the convective acceleration. As shown in Figure 3, these four nondimensional parameters determine all ratios among all force terms appear in each FSI system. Hence, each FSI system can be specified using these four nondimensional parameters, and the dynamic similarity between two different FSI systems can be measured as their distance in the nondimensional parameter space.
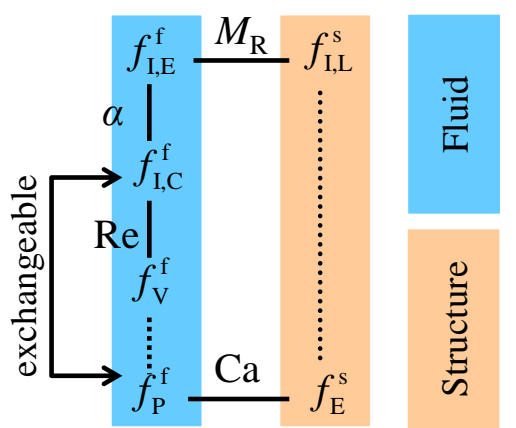

$f_{\mathrm{I}, \mathrm{E}}^{\mathrm{f}}:$ inertial force due to local acceleration $f_{\mathrm{I}, \mathrm{C}}^{\mathrm{f}}$ : inertial force due to convection $f_{\mathrm{V}}^{\mathrm{f}}$ : viscos force $f_{\mathrm{P}}^{\mathrm{f}}$ : pressure

$f_{\mathrm{I}, \mathrm{L}}^{\mathrm{f}}$ : inertial force

$f_{\mathrm{E}}^{\mathrm{f}}$ : elastic force

Figure 3. Schematic view of the present dynamic similarity framework. 


\subsection{Design Window (DW) Search}

Similar to the structural design of micro-electro-mechanical systems [10], the conceptual, basic, and detailed design processes of FWNAVs will be indistinguishable from each other. Hence, the formulation as a single design problem is difficult in each design process. Furthermore, the feasibility of the design solution is strongly constrained by the manufacturability, which is hardly formulated as the design problem.

In this study, DWs are searched in the design parameter space using the simulation based on the direct numerical modeling of the FSI. The DW is an existing area of satisfactory solutions in a design parameter space. The final solution can be adaptively chosen from the DWs taking into account other conditions such as the change given to the design problem and the manufacturability.

\section{Numerical Test for Dynamic Similarity Framework}

\subsection{Problem Setup}

The lumped torsional flexibility model is used in this study. The concept of this model is illustrated in Figure 4. In this model, the characteristic quantities $L, T, V$, and $C$ in Section 2.3 are given as the mean chord length $c_{\mathrm{w}}$, the mean flapping velocity $V_{\mathrm{m}}$, the inverse of the flapping frequency $1 / f_{\varphi}$, and the wing's torsional compliance $C_{\theta}$, respectively. $V_{\mathrm{m}}$ can be expressed as $2 r_{2} \Phi L_{\mathrm{w}} f_{\varphi}$, where $r_{2}$ is the nondimensional radius of the second moment of the wing's area, $\Phi$ is the stroke angle, and $L_{\mathrm{W}}$ is the wing's longitudinal length. Then, Equations (21)-(24) are reduced to

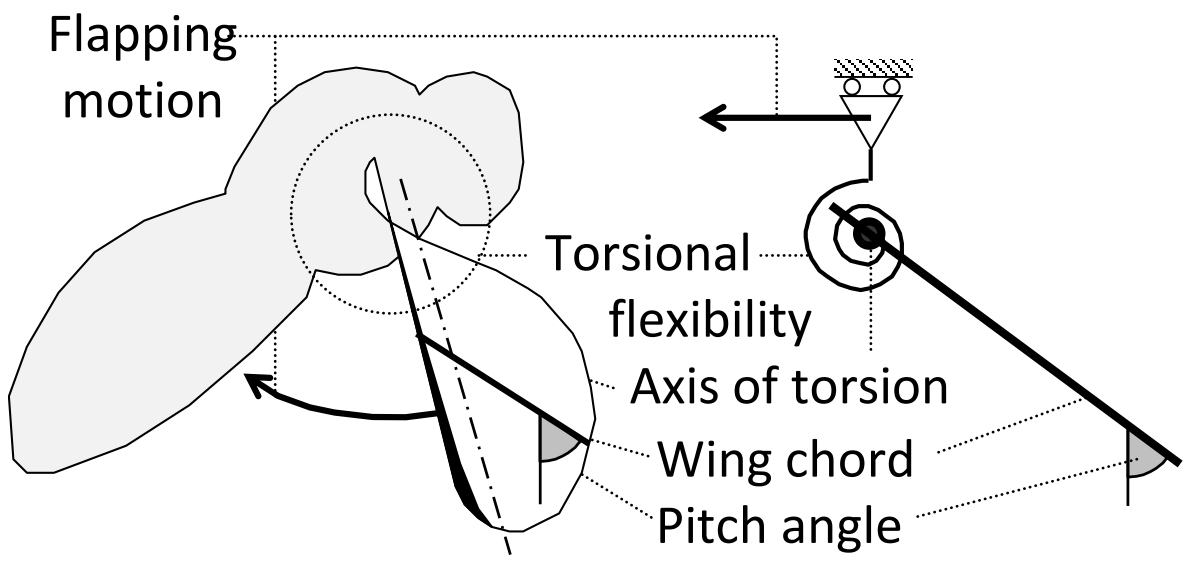

Figure 4. Concept of the lumped torsional flexibility model.

$$
\begin{gathered}
\alpha=f_{\varphi} c_{\mathrm{w}} / V_{\mathrm{m}}=1 /\left(r_{2} r_{\mathrm{A}} \Phi\right) \\
\operatorname{Re}=\rho^{\mathrm{f}} c_{\mathrm{w}} V_{\mathrm{m}} / \mu^{\mathrm{f}} \\
\mathrm{Ca}=\rho^{\mathrm{f}} V_{\mathrm{m}}^{2} c_{\mathrm{w}}^{3} c_{\theta} \\
M_{\mathrm{R}}=m_{\mathrm{w}} /\left(\rho^{\mathrm{f}} c_{\mathrm{w}}^{3}\right)
\end{gathered}
$$

where $r_{\mathrm{A}}$ is the wing's aspect ratio defined as $2 L_{\mathrm{w}} / c_{\mathrm{W}}$. As an implementation of the lumped torsional flexibility model, the rectangular wing and the plate spring are used as shown in Figure 5a. $r_{2}$ of the rectangular wing is $1 / 3^{0.5}$, which is close to that of many insect wings [63]. Hence, this shape is used for the purpose of simplicity. The finite element model is shown in Figure 5b, where MITC shell elements [58,59] are used. The fluid domain is rectangular as shown in Figure 6a. The no-slip condition is imposed to all boundaries on the wall. The finite element mesh for the fluid domain is shown in Figure $6 \mathrm{~b}, \mathrm{~d}$, where linear equal-order-interpolation velocity-pressure elements [60] are used. Based on the observation of actual insects [11], the time history of the flapping angular velocity is given using the trapezoidal function. Following this time history, the time history of the flapping 
angular displacement is given as shown in Figure 7, which is close to the sinusoidal motion after the initial transient phase.

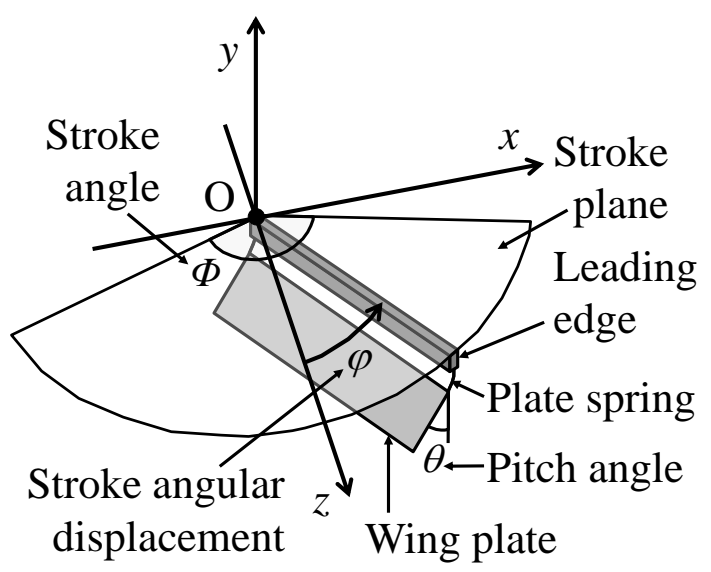

(a)

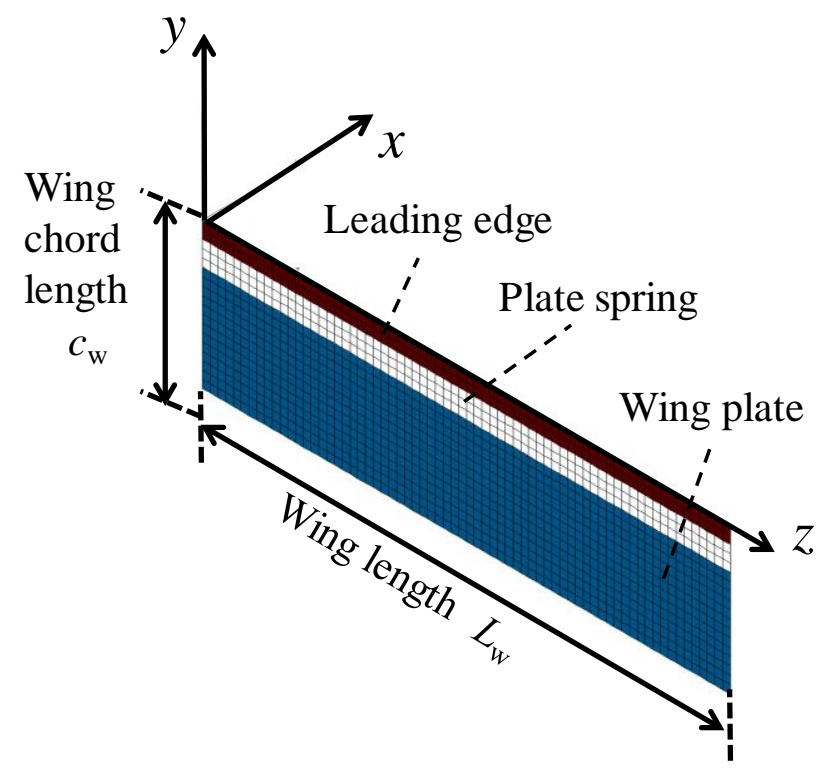

(b)

Figure 5. An implementation of the lumped torsional flexibility model using the rectangular wing and the plate spring: (a) Schematic view of the model; (b) The finite element model using shell elements. The number of shell elements is 1244 , and the number of shell nodes is 1311.

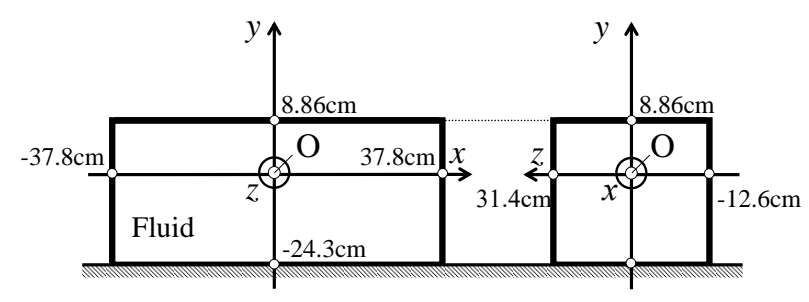

(a)

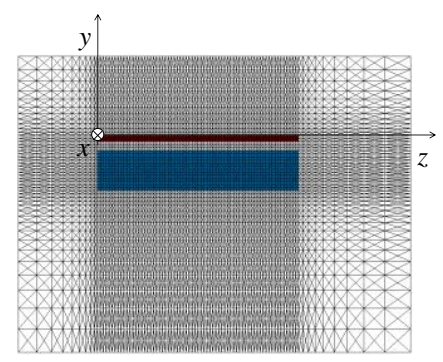

(c)

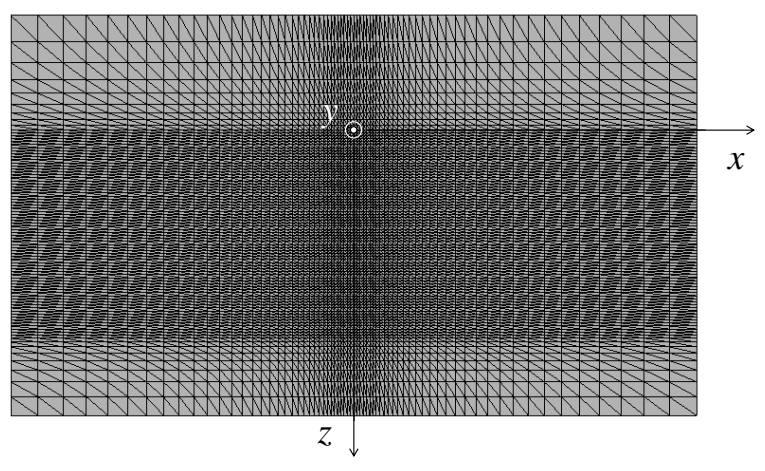

(b)

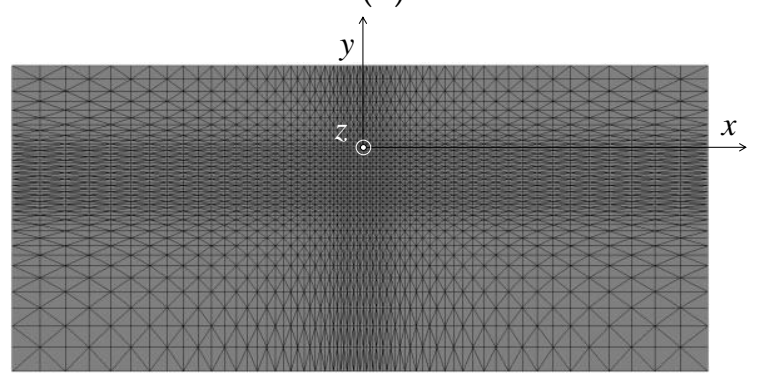

(d)

Figure 6. Geometry of the fluid domain and the employed mesh: (a) The geometry of the fluid domain (dynamically scaled); (b) The $x z$-plane view; (c) The $y z$-plane view, where the colored domain shows the wing's mesh; (d) The $x y$-plane view. The number of fluid elements is 1,578,960 and the number of fluid nodes is 276,138 . 


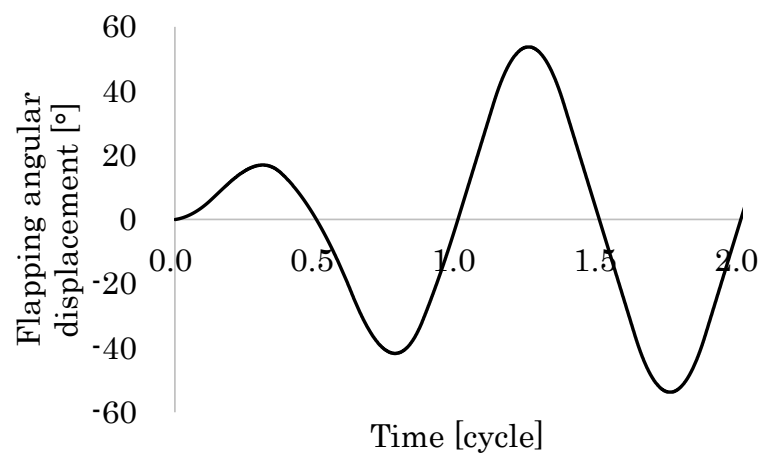

Figure 7. Time histories of the flapping angular displacement. The history during the first one cycle is for the initial transient phase.

Two different FSI systems are considered here. One is the insect wing, and the other is the dynamically scaled wing. The characteristic length of the dynamically scaled wing is 20 times larger than that of the insect wing. Following this, the values of the characteristic parameters are converted from the insect wing to the dynamically scaled wing using Equations (25)-(28). The values of the characteristic parameters for these wings are summarized in Table 1.

Table 1. Summary of the model parameters for the insect and dynamically scaled wings.

\begin{tabular}{|c|c|c|}
\hline Parameters & Insect & Dynamically Scaled \\
\hline Wing length $L_{\mathrm{W}}[\mathrm{m}]$ & 0.0113 & 0.226 \\
\hline Wing chord length $c_{\mathrm{W}}[\mathrm{m}]$ & 0.00311 & 0.0622 \\
\hline Density of the fluid $\rho^{\mathrm{f}}\left[\mathrm{kg} / \mathrm{m}^{3}\right]$ & 1.205 & 955 \\
\hline Viscosity of the fluid $\mu^{\mathrm{f}}$ [Pa s] & $1.80 \times 10^{-5}$ & $2.87 \times 10^{-2}$ \\
\hline Flapping frequency $f_{\varphi}[\mathrm{Hz}]$ & 160.5 & 0.809 \\
\hline Wing mass $m_{\mathrm{W}}[\mathrm{kg}]$ & $4.0332 \times 10^{-9}$ & $2.5577 \times 10^{-2}$ \\
\hline Torsional compliance $C_{\theta}[1 /(\mathrm{N} \mathrm{m})]$ & $432 \times 10^{3}$ & 6.71 \\
\hline Stroke angle $\Phi[\mathrm{deg}]$ & & 107.5 \\
\hline$\alpha$ & & 0.127 \\
\hline $\operatorname{Re}$ & & 824 \\
\hline $\mathrm{Ca}$ & & 0.244 \\
\hline$M_{\mathrm{R}}$ & & 0.111 \\
\hline
\end{tabular}

\subsection{Results and Discussion}

The purpose of this test is to demonstrate that the present dynamic similarity framework can make two different FSI systems dynamically similar to each other. For this purpose, the pitching angular displacement and the nondimensional lift are used, since the former is the representative characteristic quantity of the structure in the passive pitching motion, and the latter is the representative characteristic quantity of the surrounding fluid. Here, the lift force is defined as the total fluid force acting on the wing in the direction perpendicular to the stroke plane.

The present FSI system is geometrically similar to that in Reference [29], and their nondimensional parameters $\left(\alpha, \mathrm{Re}, \mathrm{Ca}\right.$, and $\left.M_{\mathrm{R}}\right)$ are close to those in Reference [29]. The mesh used in Reference [29] had the sufficient resolution for the lift force. The mesh used in this study has the finer resolution.

Figure $8 \mathrm{a}, \mathrm{b}$ show the time histories of the pitching angle and the nondimensional lift, respectively. As shown in Figure 8a, the transient large deformations in the insect wing and the dynamically scaled wing agree well with each other. Similarly, as shown in Figure 8b, the surrounding flow dynamics of these two wings agree well with each other. That is, these wings strongly coupled with the surrounding fluid flows are dynamically similar to each other. Ca represents the ratio of the fluid dynamic pressure to the structural elastic force. In Figure $8 \mathrm{a}, \mathrm{Ca}$ contributes the equivalence of the pitching angles, since they are 
determined by the equilibrium between the wing and the surrounding fluid. It follows from these results that the present dynamic similarity framework works well to make two different FSI systems dynamically similar to each other.

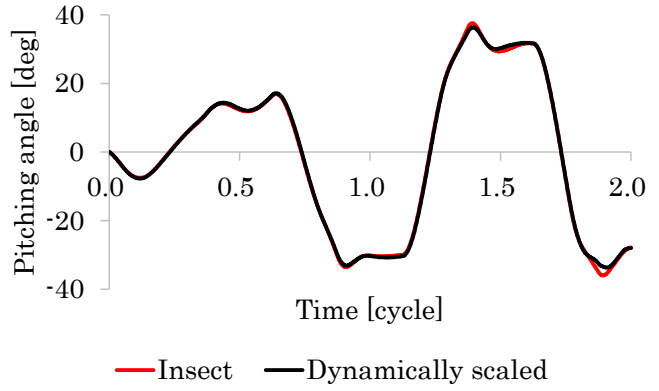

(a)

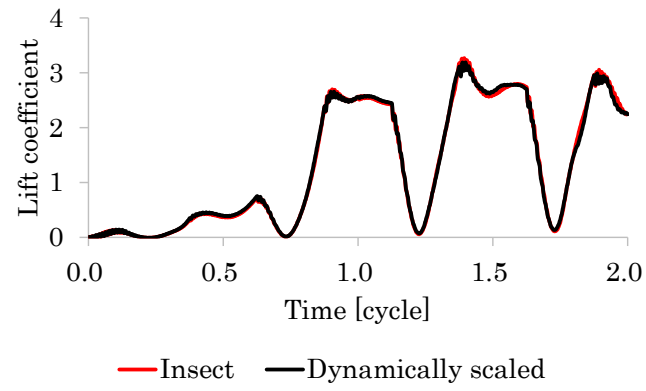

(b)

Figure 8. Time histories of (a) the pitching angular displacement and (b) the nondimensional lift.

\section{Effect of Flapping Frequency on Passive Wing Motion}

One of key parameters in insect flapping wings will be the flapping frequency. However, multiple material and kinematical properties, and complicated fluid and structural forces might prevent us from systematic understanding of its effect on the wing's passive pitching motion. The dynamic similarity law can reduce these properties and forces to only four nondimensional parameters. Hence, the framework using this law will work as the guideline for the systematic investigation of the effect of the flapping frequency on the passive pitching motion.

\subsection{Problem Setup}

The basic setup is the same as that in Section 3.1. The mesh used here is the same one as Reference [29]. The nondimensional parameters for the cranefly are used as the reference values, which are $\alpha=0.073, \mathrm{Re}=254, \mathrm{Ca}=0.19, M_{\mathrm{R}}=16, \Phi=123^{\circ}$, and $r_{\mathrm{A}}=10.7$ [29]. Here, the following dynamic similarity framework is used for the systematic investigation of the effect of the flapping frequency $f_{\varphi}$ on the passive pitching motion:

The frequency ratio $F_{\mathrm{r}}$ is used as the control parameter, which is defined as $f_{\mathrm{n}} / f_{\varphi}$, where $f_{\mathrm{n}}$ is the natural frequency of the wing's torsion. $F_{\mathrm{r}}$ is changed such that the product $\alpha F_{\mathrm{r}}$ is kept constant ( $\Phi$ and $f_{\varphi}$ are changed to change $\alpha$ and $F_{\mathrm{r}}$, respectively), while $\mathrm{Re}, \mathrm{Ca}$, and $M_{\mathrm{R}}$ are kept constant. The four cases shown in Table 2 are investigated.

Table 2. The dynamic similarity framework for the systematic investigation of the effect of the flapping frequency on the passive pitching motion.

\begin{tabular}{cccccccc}
\hline Case & $\boldsymbol{F}_{\mathbf{r}}$ & $\boldsymbol{\alpha}$ & $\boldsymbol{f}_{\boldsymbol{\varphi}}[\mathbf{H z}]$ & $\boldsymbol{\Phi}\left[^{\circ}\right]$ & $\boldsymbol{M}_{\mathbf{R}}$ & $\mathbf{R e}$ & $\mathbf{C a}$ \\
\hline 1 & 3.32 & 0.112 & 0.801 & 80 & & & \\
2 & 4.14 & 0.0892 & 0.641 & 100 & & & \\
3 & 5.10 & 0.0726 & 0.521 & 123 & & 254 & 0.19 \\
4 & 5.80 & 0.0637 & 0.458 & 140 & & & \\
\hline
\end{tabular}

\subsection{Results and Discussion}

Figure $9 \mathrm{a}, \mathrm{b}$ show the time histories of the pitching angular displacement and the nondimensional lift, respectively. In the middle of each half stroke in insect flapping wings, the dynamic pressure and the elastic force are dominant or the fluid and structural inertial forces are significantly damped [30]. Here, Ca values are same among different $F_{\mathrm{r}}$. Hence, in Figure 9a, the pitch angles in the middle of each half stroke are almost equivalent among 
different $F_{\mathrm{r}}$. On the contrary, the first peak of the pitch angle in each half stroke increases following the decrease of $F_{\mathrm{r}}$. This can be explained as follows:

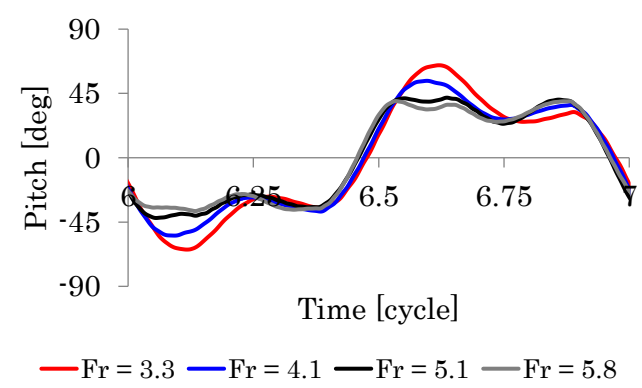

(a)

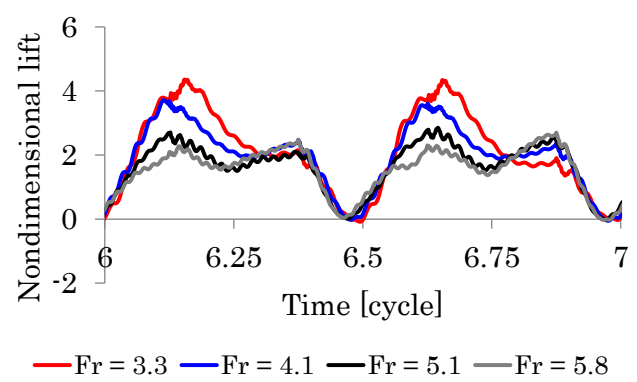

(b)

Figure 9. Time histories of (a) the pitching angular displacement, and (b) the nondimensional lift for the various frequency ratios.

As shown in Table 2, $\alpha$ increases as $F_{\mathrm{r}}$ decreases. The increase of $\alpha$ corresponds to the increase of the ratio of the inertial force to the convective and elastic forces, since $M_{R}, R e$, and $\mathrm{Ca}$ are kept constant. The inertial effect for the pitching motion is most significant just after the stroke reversal [30]. Hence, the first peak of the pitch angle in each half stroke increases following the decrease of $F_{\mathrm{r}}$.

As shown in Figure $9 \mathrm{~b}$, the first peak of the nondimensional lift in each half stroke increases as $F_{\mathrm{r}}$ decreases. Figure 10a,b show the flow fields for $F_{\mathrm{r}}=3.3$ and 5.1, respectively, at the time instant of 6.65 cycle when the nondimensional lift takes the first peak in the second half stroke. Note that the flow fields are considered on the cylindrical planes, of which normal direction coincides with the wing's longitudinal direction. The objectives of these figures are to show the present analysis captured the most important flow structure and to explain why the first lift peak during each half stroke in the case of $F_{\mathrm{r}}=3.3$ is larger than that in the case of $F_{\mathrm{r}}=5.1$. The characteristic vortex on the leading edge or the leading-edge vortex, which is one of most important flow structures in insect flapping wings [62], was formed clearly in each figure. The large translational lift in the middle of each half stroke is given by the stable attachment of this vortex on the wing.

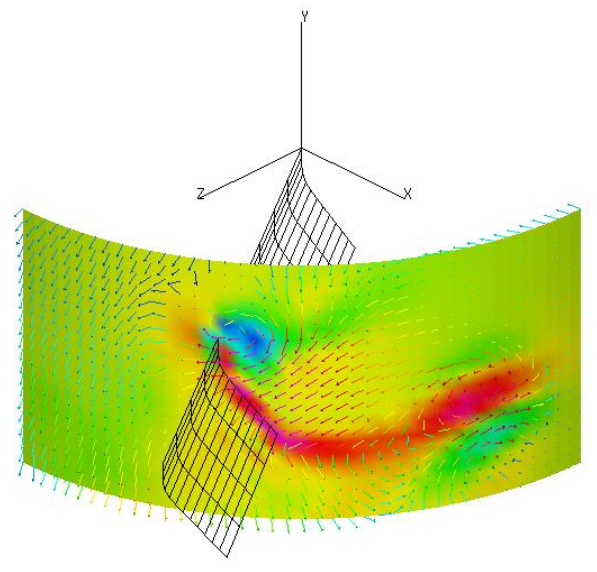

(a)

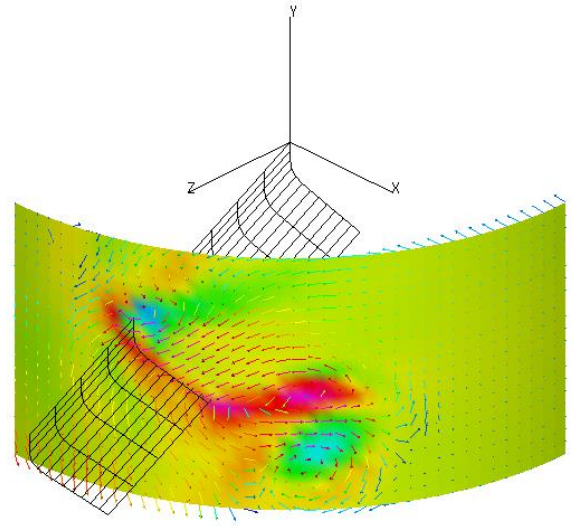

(b)

Figure 10. Flow fields on the cylindrical plane crossing the flapping wing at the time instant of 6.65 cycle when the nondimensional lift takes the first peak in the second half stroke: (a) $\Phi=123^{\circ}$, $F_{\mathrm{r}}=5.1, \alpha=0.073 ;(\mathbf{b}) \Phi=80^{\circ}, F_{\mathrm{r}}=3.3, \alpha=0.11$. In each cylindrical plane, the color contour shows the magnitude of the vorticity in the wing's longitudinal direction, the arrows show the fluid velocity field, and the color of each arrow shows the magnitude of the velocity. 
As shown in these figures, the magnitude of the downflow in front of the wing in the case of $F_{\mathrm{r}}=3.3$ is larger than that in the case of $F_{\mathrm{r}}=5.1$. That is, the downward momentum given to the fluid from the wing's flapping motion in the case of $F_{\mathrm{r}}=3.3$ is larger than that for $F_{r}=5.1$ at this time instant. As the reaction from the fluid, the first lift peak during each half stroke in the case of $F_{\mathrm{r}}=3.3$ is larger than that in the case of $F_{\mathrm{r}}=5.1$.

\section{Micro Flapping Wing with 2.5-D Structure}

In this section, the possibility of the micro flapping wing for FWNAVs is demonstrated using the proposed approach. Figure 11 shows the concept of the proposed micro flapping wing using the FSI design. As shown in this figure, the pitching motion is caused by the FSI. Furthermore, the base excitation given by a micro actuator is amplified to obtain the sufficient amplitude of the flapping motion using the resonance. Here, the flapping frequency is chosen as the design parameter since it is a key parameter for the passive pitching motion as shown in the previous section. As illustrated in Figure 12a as well as Figure 11, the most significant feature of the proposed wing is the 2.5-D structure. This structure is the engineering alternative of the nature's solution such that it can be fabricated using the micromachining technique based on the photolithography in the MEMS technology. Figure $12 b$ shows the prototyping of this wing using a polymer micromachining $[7,8,40]$.

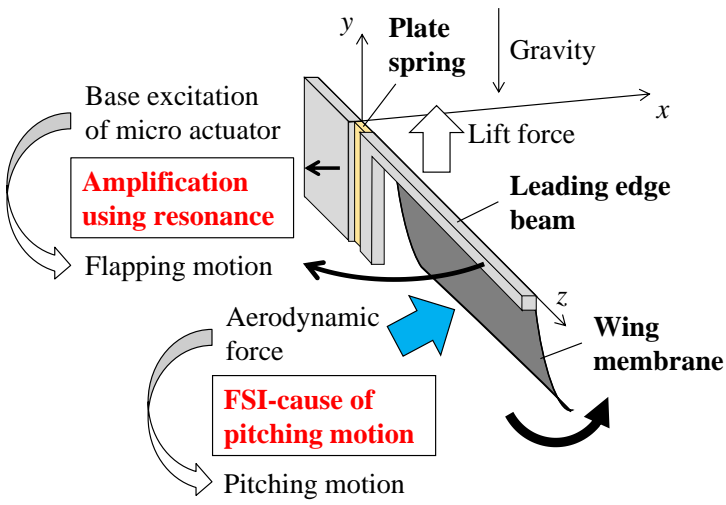

Figure 11. Conceptual view of the 2.5-dimensional wing using the FSI design.

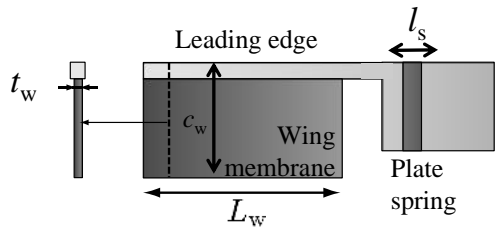

(a)

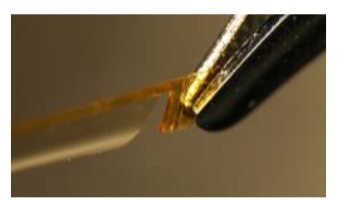

(b)

Figure 12. Detailed view of the 2.5-dimensional wing: (a) In-plane view and the dimensional parameters; (b) an example of prototyping of this wing using the micromachining technique. In this example, the wing chord length is $c_{\mathrm{W}}=2.8 \mathrm{~mm}$.

\subsection{Problem Setup}

The wing membrane is made of the polyimide (the mass density $\rho^{\mathrm{s}}=1.43 \mathrm{~g} / \mathrm{cm}^{3}$, the Young's modulus $E=3 \mathrm{GPa}$, and the Poisson's ratio $v=0.4$ ), the span length $L_{\mathrm{w}}=2.5 \mathrm{~mm}$, the chord length $c_{\mathrm{W}}=0.8 \mathrm{~mm}$, and the thickness $t_{\mathrm{w}}=1.6 \mu \mathrm{m}$, which are comparable to those of small flies. The leading edge is made of the single crystal silicon (the mass density $\rho^{\mathrm{s}}=2.383 \mathrm{~g} / \mathrm{cm}^{3}$, the Young's modulus $E=180 \mathrm{GPa}$, and the Poisson's ratio $v=0.3$ ), and the cross section is $100 \mu \mathrm{m}$ width and $50 \mu \mathrm{m}$ thickness. The plate spring is made of the same material of the wing membrane, and the spring length $l_{\mathrm{s}}$ is set as $50 \mu \mathrm{m}$. The surrounding fluid is considered as air (the mass density $\rho^{\mathrm{f}}=1.18 \times 10^{-3} \mathrm{~g} / \mathrm{cm}^{3}$, the viscosity $\left.\mu=1.82 \times 10^{-4} \mathrm{~g} /(\mathrm{cm} \times \mathrm{s})\right)$. 
The amplitude and flapping frequency of the micro actuator are assumed as follows: The amplitude of the base excitation displacement in the $x$-direction $u_{0}$ (see Figure 11) is set as $80 \mu \mathrm{m}$, which should be smaller than $100 \mu \mathrm{m}$ taking into account the available micro actuator [7,8], and the flapping frequency $f_{\varphi}$ is chosen from $100 \mathrm{~Hz}$ to $1000 \mathrm{~Hz}$ based on actual insects. The objective of the design is to find the solution that can generate the mean lift $F_{\mathrm{L}}$ larger than $7 \mu \mathrm{N}$, which is equivalent to the weight of small flies.

MITC shell elements $[58,59]$ are used for a thin elastic structure, which consists of the beam of the leading edge, the plate spring, and the wing membrane (number of nodes: 225, number of elements: 196). As shown in Figure 13b, the plate spring is modeled as a part of the beam of the leading edge at its base. In this modeling, the Young's modulus is used to keep the spring constant.

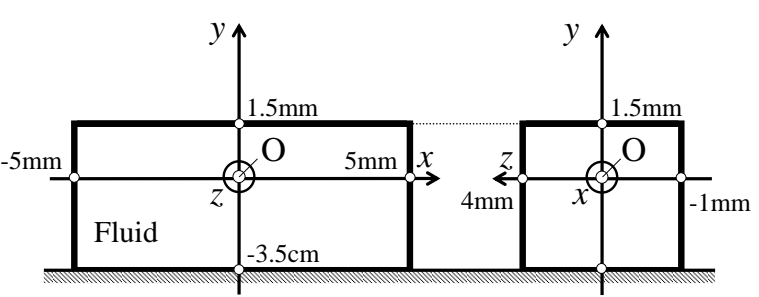

(a)

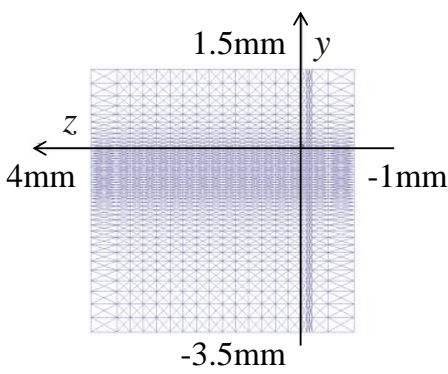

(c)

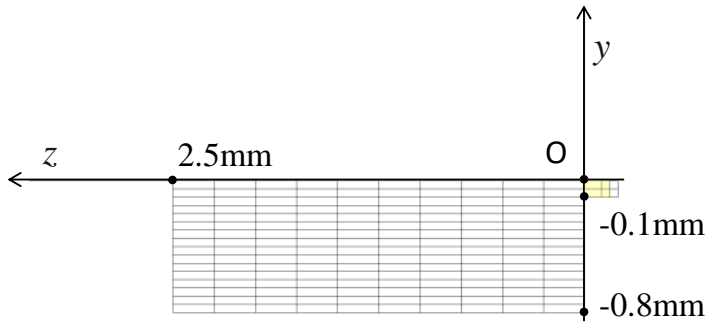

(b)

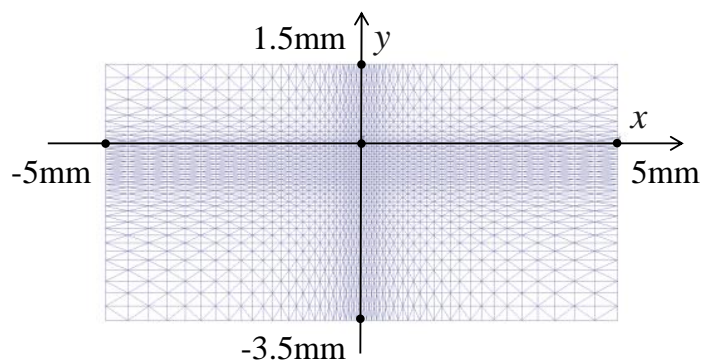

(d)

Figure 13. Geometry of the fluid domain and the employed meshes: (a) The geometry of the fluid domain; (b) The yz-plane view of the wing's mesh, where the domain colored by yellow is the plate spring; (c) The $y z$-plane view of the fluid domain; (d) The $x y$-plane view of the fluid domain.

The fluid domain is rectangular as shown in Figure 13a. The no-slip condition is imposed to all boundaries on the wall. Stabilized linear equal-order-interpolation velocitypressure elements [60] are used for the fluid. The fluid mesh is shown in Figure 13c,d. In this mesh, the number of nodes is 46,911 and the number of elements is 254,352 . Note that the resolution of the fluid mesh is almost equivalent to that in Reference [29]. The time increment $\Delta t$ is set as $T_{\varphi} / 5000$, where $T_{\varphi}$ is the flapping period. For the parametric study, the parallel computation in Section 2.2.4 is executed in a multiple core processor (10-core Xeon $2.8 \mathrm{GHz} \times 2$ CPUs, 32 GB memory).

\subsection{Results and Discussion}

In the time histories of the $x$-displacement of the wing's tip and base in the case of $f_{\varphi}=428 \mathrm{~Hz}$, the wing tip displacement was 19 times larger than the wing base displacement because of the resonance as shown in Figure 14a. Figure $14 \mathrm{~b}$ shows the time history of the flapping angular displacement. The stroke angle reaches about $73^{\circ}$ at the quasi-steady state, which is comparable to the stroke angle in actual insects. 


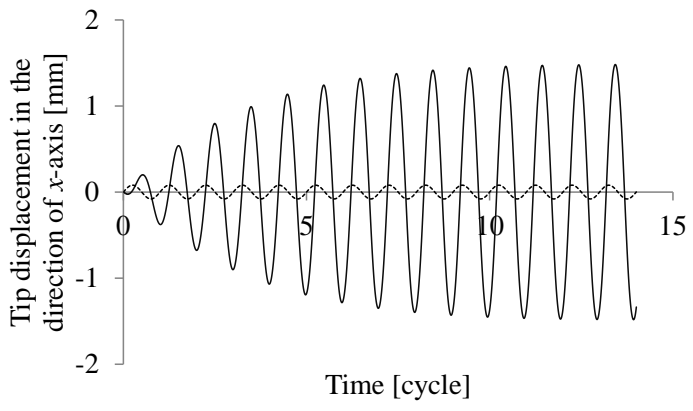

(a)

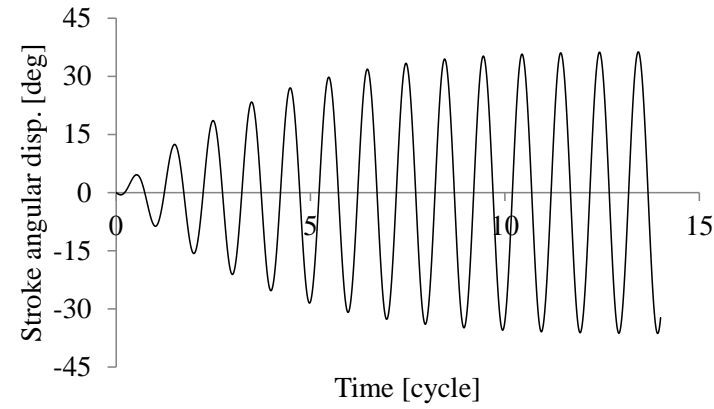

(b)

Figure 14. Time histories of (a) the tip displacement (solid line) and the base displacement (dotted line) in the $x$-direction and (b) the flapping angular displacement.

Figure 15a shows the time history of the pitching angular displacement. As shown in this figure, the passive pitching motion is caused by the FSI periodically following the flapping motion, and the pitch angle reaches $62^{\circ}$, which is comparable to the pitch angle in actual insects. Figure 15b shows the time history of the lift from a pair of the wings. As shown in this figure, the average lift is larger than the weight of the small fly $(7 \mu \mathrm{N})$.

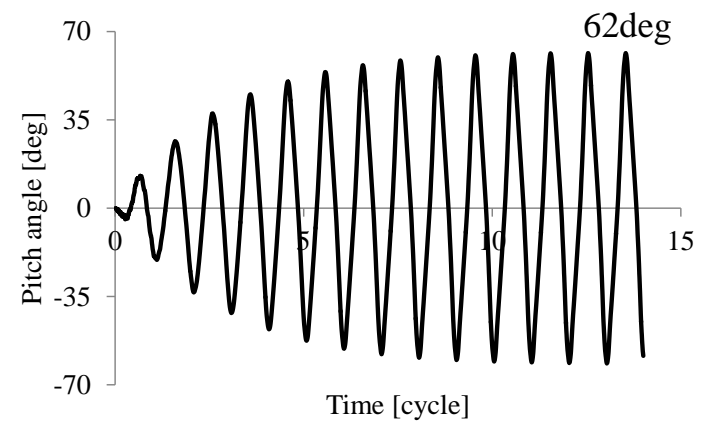

(a)

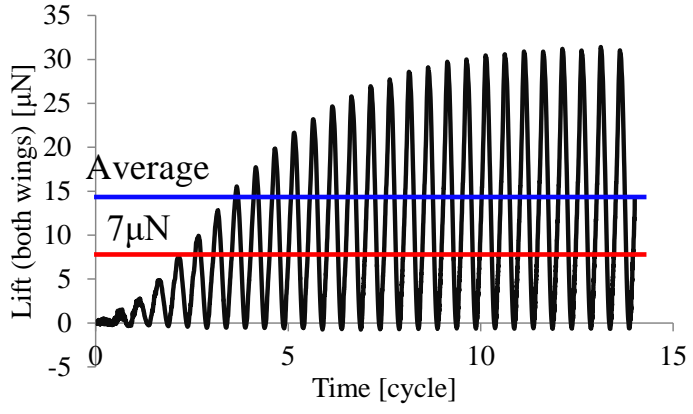

(b)

Figure 15. Time histories of (a) the pitching angular displacement, and (b) the lift.

Figure 16 shows the wing's motion and the surrounding flow. In the left column of this figure, during the upstroke, the wing flaps from right to left. In the right column of this figure, during the downstroke, the wing flaps from left to right. As shown in these figures, the passive pitching motion similar to that observed in actual insects is given by the FSI adequately. That is, the wing keeps a high angle of attack in the middle of each half stroke, and it rotates quickly during the stroke reversals. The leading-edge vortex, which is one of most important flow structures in insect flapping wings [62], was formed clearly in each figure. These figures also show the stable attachment of this vortex on the wing. This stable attachment contributes the large translational lift in the middle of each half stroke.

Finally, the DW search was done based on the frequency response functions (FRFs). Using the FRF for the mean lift, which is shown in Figure 17a, the DW is given as the flapping frequency area ranging from $410 \mathrm{~Hz}$ to $460 \mathrm{~Hz}$ approximately. That is, the proposed wing using any frequency in this DW generates the sufficient lift to support the weight of the small fly $(7 \mu \mathrm{N})$. Figure $17 \mathrm{~b}$ shows the FRF for the stroke angle. As shown in this figure, the stroke angle is larger than $50^{\circ}$ approximately in the DW, which is comparable to the stroke angle in actual insects. It follows from these results that the possibility of the micro flapping wing for FWNAVs is demonstrated. 


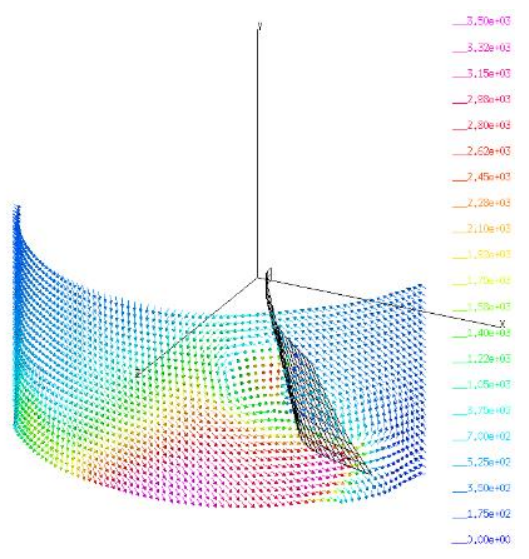

(a)

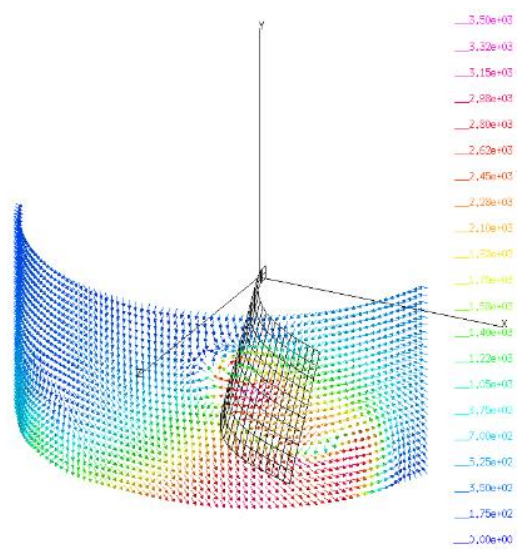

(b)

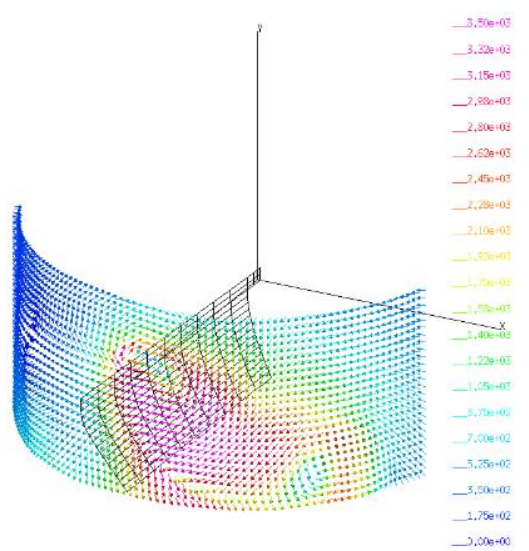

(c)

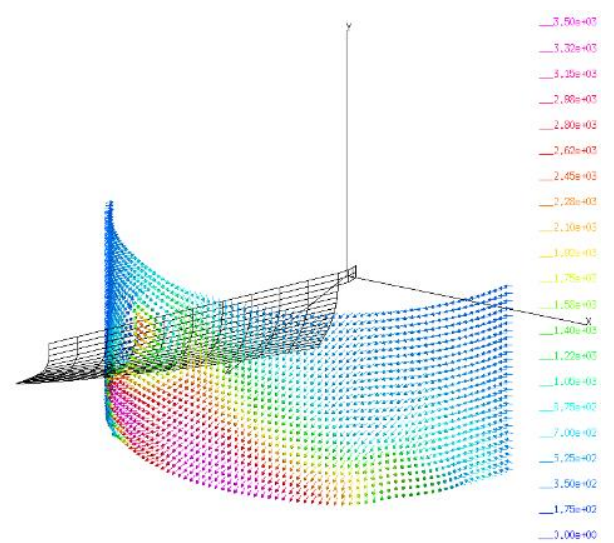

(e)

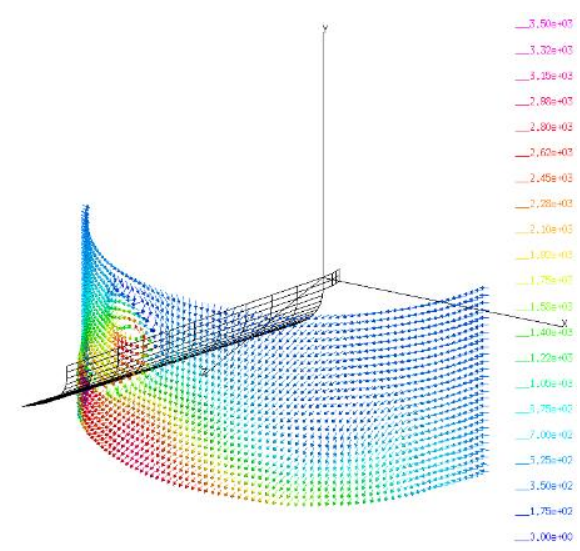

(f)

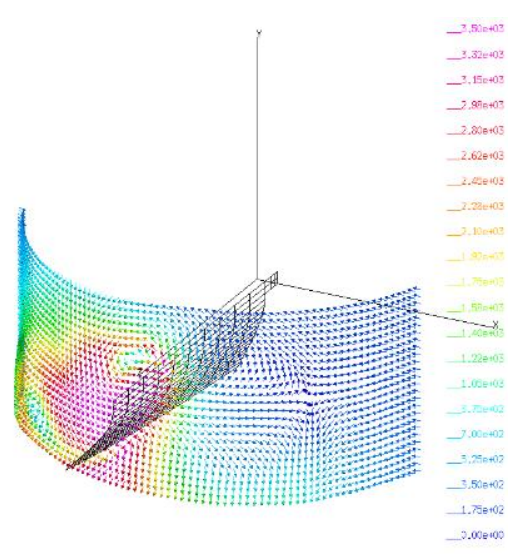

(g)

Figure 16. Cont. 


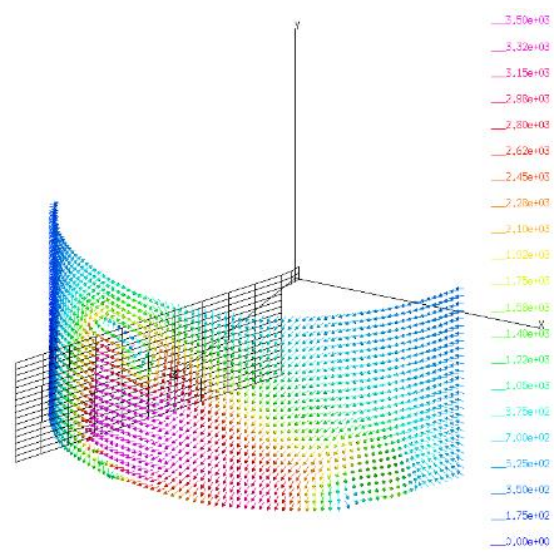

(d)

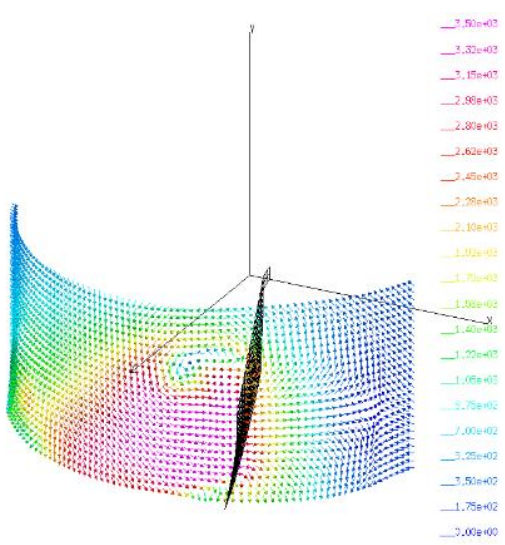

(h)

Figure 16. Wing's flapping motion and the surrounding flow during the upstroke, where the wing flaps from right to left in the left column, and the wing flaps from left to right in the right column: (a) The time instant of 8.48 cycle; (b) The time instant of 8.60 cycle; (c) The time instant of 8.72 cycle; (d) The time instant of 8.84 cycle; (e) The time instant of 8.96 cycle; (f) The time instant of 9.08 cycle; (g) The time instant of 9.20 cycle; (h) The time instant of 9.32 cycle.

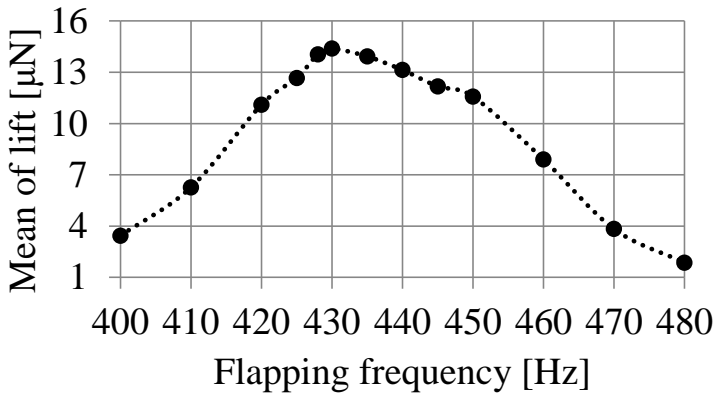

(a)

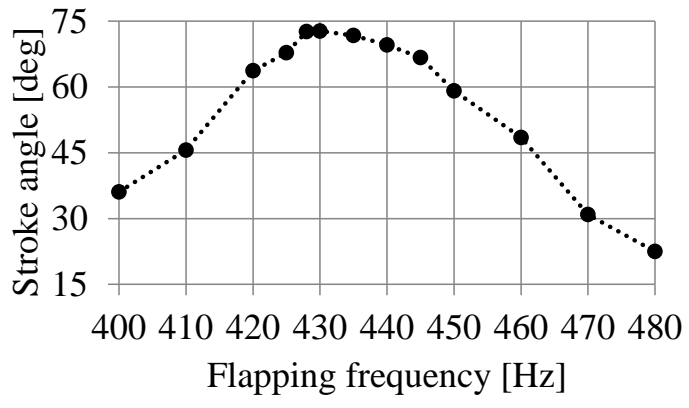

(b)

Figure 17. Frequency response functions of (a) the mean lift and (b) the stroke angle.

\section{Conclusions}

In this study, the computational approach for the FSI design of insect-inspired micro flapping wings was developed. This approach consists of the simulation based on the direct numerical modeling of the strongly coupled FSI, the dynamic similarity framework, and the design window search. The key of the FSI design is the accurate prediction for the 3-D strong coupling of the thin flexible flapping wing and the surrounding air flow. Here, a projection method using the algebraic splitting was used to solve this problem directly. It seems that there are few studies about computational approaches for the FSI design of FWNAVs, where a flight device actively uses the FSI to create the characteristic wing's motions to reduce the mechanical and electrical complexities of this device.

In the first numerical example, it was demonstrated that the dynamic similarity law for the FSI makes two different lumped torsional flexibility models strongly coupled with the surrounding fluids dynamically similar with each other.

In the second numerical example, the effect of the flapping frequency on the passive pitching motion was systematically investigated using the dynamic similarity framework, which worked as the guide for the complexities of this FSI.

Finally, in the last numerical example, an insect-inspired micro flapping wing with the 2.5-D structure was designed using the proposed approach. The proposed wing was the 
engineering alterative for the nature's solution in actual insects such that it can be fabricated using the microfabrication based on the photolithography in the MEMS technology. Here, the flapping frequency was taken as the design parameter. The DW was found such that each solution in the DW can generate the lift sufficient to support the weight of small insects.

In future work, this wing will be fabricated using the micromachining. Hence, the proposed approach will contribute to the further miniaturization of FWNAVs.

Funding: This research was supported by the Japan Society for the Promotion of Science under KAKENHI Grant No. 20H04199.

Institutional Review Board Statement: Not applicable.

Informed Consent Statement: Not applicable.

Data Availability Statement: The datasets analyzed during the current study are available from the corresponding author on reasonable request.

Conflicts of Interest: The author declares no conflict of interest.

\section{References}

1. Azuma, A. The Biokinetics of Flying and Swimming; AIAA Education Series; American Institute of Aeronautics and Astronautics, Inc.: Reston, VA, USA, 2005.

2. Dudley, R. The Biomechanics of Insect Flight: Form, Function, Evolution; Princeton University Press: Princeton, NJ, USA, 2002.

3. Brodsky, A.K. The Evolution of Insect Flight; Oxford Science Publication: Oxford, UK, 1994.

4. Liu, H.; Nakata, T.; Li, G.; Kolomenskiy, D. Biomechanics and biomimetics in flying and swimming. In Industrial Biomimetics; Jenny Stanford Publishing: Dubai, United Arab Emirates, 2019; pp. 29-80.

5. Liu, H.; Ravi, S.; Kolomenskiy, D.; Tanaka, H. Biomechanics and biomimetics in insect-inspired flight systems. Philos. Trans. R. Soc. 2016, B371, 20150390. [CrossRef]

6. Zhang, C.; Rossi, C. A review of compliant transmission mechanisms for bio-inspired flapping-wing micro air vehicles. Bioinspir Biomim. 2017, 12, 025005. [CrossRef]

7. Ishihara, D.; Murakami, S.; Ohira, N.; Ueo, J.; Takagi, M.; Urakawa, K.; Horie, T. Polymer micromachined transmission for insect-inspired flapping wing nano air vehicles. In Proceedings of the 15th Annual IEEE International Conference on Nano/Micro Engineered and Molecular Systems, San Diego, CA, USA, 27-30 September 2020; pp. 27-30.

8. Rashmikant; Ishihara, D.; Suetsugu, R.; Ramegowda, P.C. One-wing polymer micromachined transmission for insect-inspired flapping wing nano air vehicles. Eng. Res. Express 2021, 3, 045006. [CrossRef]

9. $\quad$ Pringle, J.W.S. Insect Flight; Cambridge University Press: Cambridge, UK, 1957.

10. Ishihara, D.; Jeong, M.J.; Yoshimura, S.; Yagawa, G. Design window search using continuous evolutionary algorithm and clustering -its application to shape optimization of microelectrostatic actuator. Comput. Struct. 2002, 80, 2469-2481. [CrossRef]

11. Ellington, C.P. The aerodynamics of hovering insect flight. III. Kinematics. Philos. Trans. R. Soc. 1984, B305, 41-78.

12. Dickinson, M.H.; Lehmann, F.-O.; Sane, P.S. Wing rotation and the aerodynamic basis of insect flight. Science 1999, 284, 1954-1960. [CrossRef] [PubMed]

13. Wootton, R.J. Support and deformability in insect wings. J. Zool. Lond. 1981, 193, 447-468. [CrossRef]

14. Ennos, A.R. The importance of torsion in the design of insect wings. J. Exp. Biol. 1988, 140, 137-160. [CrossRef]

15. Ennos, A.R. The inertial cause of wing rotation in Diptera. J. Exp. Biol. 1988, 140, 161-169. [CrossRef]

16. Ennos, A.R. Inertial and aerodynamic torques on the wings of Diptera in flight. J. Exp. Biol. 1989, 142, 87-95. [CrossRef]

17. Combes, S.A.; Daniel, T.L. Flexural stiffness in insect wings I. Scaling and the influence of wing venation. J. Exp. Biol. 2003, 206, 2979-2987. [CrossRef]

18. Ma, Y.; Ma, T.; Ning, J.; Gorb, S. Structure and tensile properties of the forewing costal vein of the honeybee Apis mellifera. Soft Matter 2020, 16, 4057-4064. [CrossRef] [PubMed]

19. Ning, J.G.; Ma, Y.; Ren, H.L.; Zhang, P.F. Investigation of span-chordwise bending anisotropy of honeybee forewings. Biol. Open 2017, 6, 619-624. [CrossRef]

20. Ennos, A.R. The kinematics and aerodynamics of the free flight of some Diptera. J. Exp. Biol. 1989, 142, 49-85. [CrossRef]

21. Miller, L.A.; Peskin, C.S. A computational fluid dynamics of 'clap and fling' in the smallest insects. J. Exp. Biol. 2005, 208, 195-212. [CrossRef] [PubMed]

22. Young, J.; Walker, S.M.; Bomphery, R.J.; Taylor, G.K.; Thomas, A.L.R. Details of insect wing design and deformation enhance aerodynamic function and flight efficiency. Science 2009, 325, 1549-1552. [CrossRef] [PubMed]

23. Du, G.; Sun, M. Effects of wing deformation on aerodynamic forces in hovering hoverflies. J. Exp. Biol. 2010, $213,2273-2283$. [CrossRef] [PubMed]

24. Zheng, L.; Hedrick, T.L.; Mittal, R. Time-varying wing-twist improves aerodynamic efficiency of forward flight in butterflies. PLoS ONE 2013, 8, e53060. [CrossRef] [PubMed] 
25. Nakata, T.; Noda, R.; Liu, H. Effect of twist, camber and spanwise bending on the aerodynamic performance of flapping wings. J. Biomech. Sci. Eng. 2018, 13, 17-00618. [CrossRef]

26. Ishihara, D.; Horie, T.; Denda, M. A two-dimensional computational study on fluid-structure interaction cause of wing pitch changes in dipteran flapping flight. J. Exp. Biol. 2009, 212, 1-10. [CrossRef]

27. Nakata, T.; Liu, H. A fluid-structure interaction model of insect flight with flexible wings. J. Comput. Phys. 2012, 231, 1822-1847. [CrossRef]

28. Hua, R.; Zhu, L.; Lu, X. Locomotion of a flapping flexible plate. Phys. Fluids 2013, 25, 121901. [CrossRef]

29. Ishihara, D.; Horie, T.; Niho, T. An experimental and three-dimensional computational study on the aerodynamic contribution to the passive pitching motion of flapping wings in hovering flies. Bioinspir. Biomim. 2014, 9, 046009. [CrossRef] [PubMed]

30. Ishihara, D.; Horie, T. Passive mechanism of pitch recoil in flapping insect wings. Bioinspir. Biomim. 2017, 12, 016008. [CrossRef] [PubMed]

31. Shahzad, A.; Tian, F.-B.; Young, J.; Lai, J.C.S. Effect of hawkmoth-like flexibility on the aerodynamic performance of flapping on the performance of flapping wings with difference shapes and aspect ratios. Phys. Fluids 2018, 30, 091902. [CrossRef]

32. Ishihara, D. Role of fluid-structure interaction in generating the characteristic tip path of a flapping flexible wing. Phys. Rev. E 2019, 98, 032411. [CrossRef]

33. Xiao, Q.; Hu, J.; Liu, H. Effect of torsional stiffness and inertia on the dynamics of low aspect ratio flapping wings. Bioinspir. Biomim. 2014, 9, 016008. [CrossRef] [PubMed]

34. Ishihara, D.; Yamashita, Y.; Horie, T.; Yoshida, S.; Niho, T. Passive maintenance of high angle of attack and its lift generation during flapping translation in crane fly wing. J. Exp. Biol. 2009, 212, 3882-3891. [CrossRef] [PubMed]

35. Ishihara, D.; Ohira, N.; Takagi, M.; Murakami, S.; Horie, T. Fluid-structure interaction design of insect-like micro flapping wing In Proceedings of the 7th International Conference on Computational Methods for Coupled Problems in Science and Engineering, Rhodes, Greece, 12-14 June 2017; pp. 870-875.

36. Wood, R.J. The first takeoff of a biologically inspired at-scale robotic insect. IEEE Trans. Robot. 2008, 24, 341-347. [CrossRef]

37. Bathe, K.J. Finite Element Procedures; Prentice-Hall: Hoboken, NJ, USA, 1996.

38. Ishihara, D.; Yoshimura, S. A monolithic method for fluid-shell interaction based on consistent pressure Poisson equation. Int. J. Numer. Methods Eng. 2005, 64, 167-203. [CrossRef]

39. Ishihara, D.; Horie, T. A projection method for the interaction of an incompressible fluid and a structure using new algebraic splitting. Comput. Modeling Eng. Sci. 2014, 101, 421-440.

40. Murakami, S.; Ishihara, D.; Araki, M.; Horie, T.; Ohira, N.; Ito, T. Microfabrication of hybrid structure composed of rigid silicon and flexible polyimide membranes. Micro Nano Lett. 2017, 12,913-915. [CrossRef]

41. Tanaka, H.; Wood, R.J. Fabrication of corrugated artificial insect wings using laser micromachined molds. J. Micromech. Microeng. 2010, 20, 075008. [CrossRef]

42. Wootton, R.J. Functional morphology of insect wings. Annu. Rev. Entomol. 1992, 37, 113-140. [CrossRef]

43. Rees, C.J.C. Form and functions in corrugated insect wings. Nature 1975, 256, 200-203. [CrossRef]

44. Sunada, S.; Zeng, L.; Kawachi, K. The relationship between dragonfly wing structure and torsional deformation. J. Theor. Biol. 1998, 193, 39-45. [CrossRef]

45. Wang, X.S.; Li, Y.; Shi, Y.F. Effects of sandwich microstructures on mechanical behaviors of dragonfly wing vein. Compos. Sci. Technol. 2008, 68, 186-192. [CrossRef]

46. Walker, S.M.; Thomas, A.L.R.; Taylor, G.K. Deformable wing kinematics in free-flying hoverflies. J. R. Soc. Interface 2010, 7 , 131-142. [CrossRef] [PubMed]

47. Nalbach, G. The gear change mechanism of the blowfly (Calliphora erythrocephala) in tethered flight. J. Comp. Physiol. 1989, A165, 321-331. [CrossRef]

48. Dickinson, M.H.; Tub, M.S. The function of dipteran flight muscle. Comp. Biochem. Physiol. 1997, 116A, 223-238. [CrossRef]

49. Balint, C.N.; Dickinson, M.H. Neuromuscular control of aerodynamic forces and moments in the blowfly, Calliphora vicina. J. Exp. Biol. 2004, 207, 3813-3838. [CrossRef]

50. Walker, S.M.; Thomas, A.L.R.; Taylor, G.K. Operation of the alula as an indicator of gear change in hoverflies. J. R. Soc. Interface 2012, 9, 1194-1207. [CrossRef]

51. Wootton, R.J.; Herbert, R.C.; Young, P.G.; Evans, K.E. Approaches to the structural modelling of insect wings. Philos. Trans. R. Soc. Lond. 2003, B358, 1577-1587. [CrossRef] [PubMed]

52. Ishihara, D.; Yokota, J.; Onishi, M.; Niho, T.; Horie, T. A Shape simplification modeling of the cambering in insect's flapping wings using beam and shell. Trans. Jpn. Soc. Comput. Eng. Sci. 2018, 2018, 20180018.

53. Onishi, M.; Ishihara, D. Modeling the cambering of the flapping wings of an insect using rectangular shell finite elements. $J$. Adv. Simul. Sci. Eng. 2020, 7, 181-188. [CrossRef]

54. Onishi, M.; Ishihara, D. Performance evaluation of the pixel wing model for the insect wing's camber. J. Adv. Simul. Sci. Eng. 2021, 8, 163-172. [CrossRef]

55. Kesel, A.B.; Philippi, U.; Nachtigall, W. Biomechanical aspects of the insect wing: An analysis using the finite element method. Comput. Biol. Med. 1998, 28, 423-437. [CrossRef]

56. Herbert, R.C.; Young, P.G.; Smith, C.W.; Wootton, R.J.; Evans, K.E. The hind wing of the desert locust (Schistocerca Gregaria Forskal), III. A finite element analysis of a deployable structure. J. Exp. Biol. 2000, 203, 2945-2955. [CrossRef] 
57. Mengesha, T.E.; Vallance, R.R.; Barraja, M.; Mittal, R. Parametric structural modeling of insect wings. Bioinspir. Biomim. 2009, 4, 036004. [CrossRef] [PubMed]

58. Bathe, K.J.; Dvorkin, E.N. A four-node plate bending element based on Mindlin/Reissner plate theory and a mixed interpolation. Int. J. Numer. Methods Eng. 1985, 21, 367-383. [CrossRef]

59. Noguchi, N.; Hisada, T. Sensitivity analysis in post-buckling problems of shell structures. Comput. Struct. 1993, 47, 699-710. [CrossRef]

60. Tezduyar, T.E.; Mital, S.; Ray, S.E.; Shih, R. Incompressible flow computations with stabilized bilinear and linear equal-orderinterpolation velocity-pressure elements. Comput. Methods Appl. Mech. Eng. 1992, 95, 221-242. [CrossRef]

61. Zhang, Q.; Hisada, T. Analysis of fluid-structure interaction problems with structural buckling and large domain changes by ALE finite element methods. Comput. Methods Appl. Mech. Eng. 2001, 190, 6341-6357. [CrossRef]

62. Ellington, C.P.; Van den Berg, C.; Willmott, A.P.; Thomas, L.R. Leading-edge vortices in insect flight. Nature 1996, 384, 626-630. [CrossRef]

63. Ellington, C.P. The aerodynamics of hovering insect flight. II. Morphological Parameters. Philos. Trans. R. Soc. Lond. 1984, B305, $17-40$. 